\title{
The Effect of Defined Lipopolysaccharide Core Defects upon Antibiotic Resistances of Salmonella typhimurium
}

\author{
By R. J. ROANTREE, T.-T. KUO* AND D. G. MACPHEE $\dagger$ \\ Department of Medical Microbiology, Stanford University School of Medicine, \\ Stanford, California 94305, U.S.A.
}

(Received I4 June 1977)

Antibiotic resistances of two sets of Salmonella typhimurium rfa transductants (along with those of their smooth pyrE $E^{+}$and cys $E^{+}$sister transductants) were measured. One set was derived from a pyrE smooth LT2 parent and the other from a cysE smooth LT7 parent. Results showed that strains with defects at the $r f a($ R-res-2) level and deeper were more susceptible to bacitracin, novobiocin and polymyxin. Those with defects at the $r f a G$ level or deeper were in addition more sensitive to vancomycin, erythromycin, oxacillin and nafcillin. At these levels the presence or absence of galactose I or glucose I from the lipopolysaccharide core made a considerable difference. A heptose-less $r f a E$ mutant was the most sensitive of the strains tested to the above named antibiotics. Strains with $r f a$ lesions at several levels of defect showed slight increases in resistances to tetracycline, cephalothin, ampicillin and penicillin.

One would expect strains with galE mutations to be similar to $r f a(\mathrm{R}-\mathrm{res}-2)$ strains and those with galU mutations to be similar to $r f a G$ strains if the core defects accounted for the differing antibiotic resistances. They proved to be so except that the galE and galU strains in the S. typhimurium FIRN line were as resistant to novobiocin as were smooth strains.

The results are interpreted in respect to Nikaido's hypothesis that hydrophilic antibiotics with molecular weights of less than about 650 can gain access to the periplasmic space through protein-lined, water-filled pores and that hydrophobic ones can gain access in deep rough strains when phospholipid patches appear on the surface due to absence of polysaccharides and proteins.

\section{INTRODUCTION}

This report deals with the effects of defined mutations that control the polysaccharide composition of the rough core region of the lipopolysaccharide (LPS) of Salmonella typhimurium upon the sensitivity of strains containing such mutations to a battery of antibiotics. Preliminary results of these experiments have been reported (Roantree et al., I969 $a, b)$ and they agree in general with the results reported by Schlecht and his associates who investigated the antibiotic and dye resistances of rough mutant strains of several Salmonella species (Schlecht \& Schmidt, 1969, 1970, 1972; Schlecht \& Westphal, 1970).

The stimulus for this study was the observation that Salmonella mutants selected for their resistances to penicillin or cephalothin included a number of mutants belonging to several different rough classes (Nelson \& Roantree, 1967). We had available two sets of $S$. typhimurium transductants, one derived from an LT2 ( $p y r E)$ strain and one from an LT7 (cysE) strain. Thus far, most of the genes described as necessary for the attachment to each

* Present address: Department of Pathology, The University of Texas Medical Branch, Galveston, Texas 77550, U.S.A.

† Present address: Department of Genetics, La Trobe University, Bundoora, Victoria 3083, Australia. 


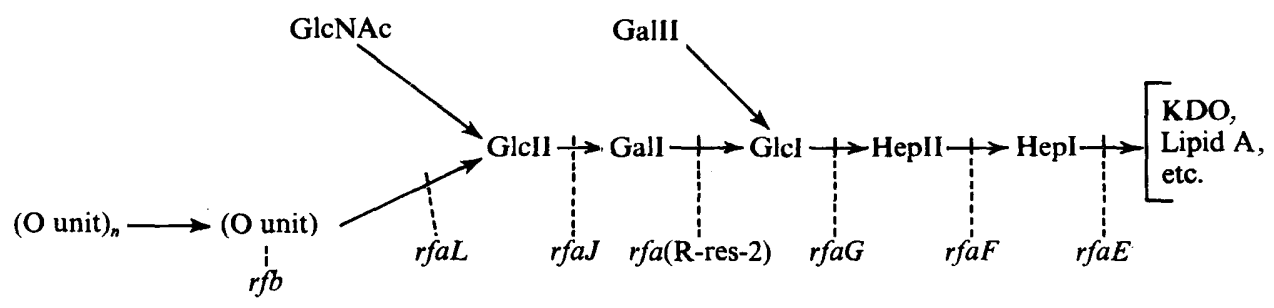

Fig. I. Main features of Salmonella lipopolysaccharide structure and symbols assigned to genes concerned with formation of individual units of the core.

other of the sugar subunits of the LPS core are located in a short region of the S. typhimurium linkage map between $c y s E$ and pyrE (Kuo \& Stocker, 1972; Sanderson \& Saeed, H., I972; Sanderson \& Saeed, Y. A., 1972). Treatment with phage ESI 8 grown on LT2 strains with different $r f a$ mutations yielded LT7 $c y s E^{+}$and LT2 $p y r E^{+}$transductants with different $r f a$ mutations, all the members of a set being isogenic except for the cysE rfa or pyrE rfa segments. Genes from the $r f a$ segment that can be cotransduced with either cysE or pyrE (Kuo \& Stocker, 1972; Sanderson \& Saeed, Y. A., 1972) include $r f a L, r f a J, r f a($ R-res-2), $r f a G$ and $r f a F$ (Fig. I). The designation $r f a($ R-res-2) is used rather than the usual uppercase letter symbol because mutants of this phage pattern although lacking galactose I (Hellerqvist \& Lindberg, I97I), do possess galactosyl transferase I (Osborn, I968).

When it became evident from studies with these and other $r f a$ strains that changes in the polysaccharide portion of the rough core probably affected resistances to a number of antibiotics in a predictable way, we used other mutants with LPS core defects (galE, galU and $r f a E$ ) to test the validity of the concept.

\section{METHODS}

Media. Difco brain-heart infusion broth (for overnight cultures) and Oxoid sensitivity test medium (CM215) agar were used for testing antibiotic sensitivities. For the derivation of the galU [deficient in UDPglucose pyrophosphorylase (Nakae \& Nikaido, 197I)] and for phage testing, we used Oxoid nutrient extract broth no. 2 (CM67) as liquid medium and Oxoid blood agar base (CM55) as solid medium. The defined medium employed was Davis minimal medium with glycerol $\left(2 \mathrm{ml} \mathrm{l}^{-1}\right)$ instead of glucose as the carbon source; citrate was omitted in tests for ability to utilize galactose.

Bacteria. The $S$. typhimurium strains constituting the two sets ( $p y r E^{+} \mathrm{LT}_{2}$ or $c y s E^{+} \mathrm{LT} 7$ ) of transductants, which were isogenic except for their $r f a$ genetic character, and their parent smooth strains are listed in Table $\mathrm{I}$. The core defects associated with each $r f a$ locus are indicated in Fig. I. galE, galU and rfaE mutants, together with their parent and derivative strains, are listed in Table 2.

Antibiotic sensitivity tests. Usually a series of to to 18 agar plates containing stepwise concentrations of antibiotics and two control plates without antibiotics were prepared for each antibiotic to be used. The plates were inoculated by use of a 25-pronged replicator, each prong of which had been dipped into $0.75 \mathrm{ml}$ bacterial suspension contained in one of the 25 compartments of a Bertani box (Elesa, Milan, Italy). The bacterial suspensions were prepared from unshaken overnight broth cultures, grown at $37^{\circ} \mathrm{C}$, by $\mathrm{r} / 2000$ dilution in saline. Thus each prong delivered roo to 200 bacteria. Control plates were inoculated first and last in each series of inoculations. The lowest concentrations of antibiotic yielding no colony or $<5 \%$ of those on the control plate after $24 \mathrm{~h}$ at $37^{\circ} \mathrm{C}$ was taken as the minimum inhibitory concentration (m.i.c.). This method allows a direct assessment of the growth of each member of a comparison group at each antibiotic concentration. The results in Tables 3 and 4 for each comparison group were obtained from one such run for each antibiotic. Two or three preliminary runs were done for each antibiotic to establish the correct range of concentrations.

Genetic methods. Methods used to derive the two sets of $r f a$ transductants listed in Table I have been reported in detail (Kuo \& Stocker, 1972). The smooth $p y r E^{+}$transductant SL3770 and smooth cys $^{+}$transductant SL3856 were derived in the same manner but did not receive any $r f a$ defect. The galE456 mutant and its smooth parent TV253 (Table 2) have been described (Krishnapillai, MacPhee \& Stocker, 1971). The mutant was given $\mathrm{F}^{\prime}$ galE by conjugation with an Escherichia coli $\mathrm{KI}_{2} \mathrm{~F}^{\prime} \mathrm{gal}^{+}$donor strain (MacPhee \& Stocker, 1969). The galU455 mutation occurred spontaneously in the TV253 strain and was selected by its 
Table I. The two rfa transductant series of Salmonella typhimurium and their parent strains

These strains are the smooth pyrE LT2 SLI5I5 recipient strain and its pyrE $E^{+}$transductional derivatives and the smooth cysE LT7 SLI 547 recipient and its $c y s E^{+}$transductional derivatives. The transduced $r f a$ loci and pyrE and $c y s E$ loci are indicated. Phage ESI 8 was used for transduction.

\begin{tabular}{|c|c|c|c|}
\hline Strain & Genotype & $\begin{array}{l}\text { Source of } \\
r f a \text { allele }\end{array}$ & Reference \\
\hline SLI 5 I 5 LT2 & pyrEI25 $r f a^{+}$smooth recipient & - & $\begin{array}{l}\text { Sanderson \& Saeed, Y.A. } \\
\text { (1972) }\end{array}$ \\
\hline SL3770 & like sLI 515 but $p y r E^{+}$ & - & see Methods \\
\hline SL3749 & like sL3770 but $r f a L 446$ & TV225 & Kuo \& Stocker (1972) \\
\hline SL3750 & like sL 3770 but $r f a J 4 I 7^{*}$ & TVI6I & Kuo \& Stocker (1972) \\
\hline SL3748 & like sL 3770 but $r f a(\mathbf{R}-$ res-2 $) 432 \dagger$ & TVI 48 & Kuo \& Stocker (1972) \\
\hline SL3769 & like sL 3770 but $r f a G 47 I$ & SLIO32 & Kuo \& Stocker (1972) \\
\hline SL3789 & like SL377o but $r f a F_{5} I r$ & SL. I I 81 & Kuo \& Stocker (1972) \\
\hline SLI 547 LT7 & $\begin{array}{l}\text { cysE30 gal-85I } \$ r f a^{+} \text {smooth } \\
\text { recipient }\end{array}$ & - & from K. E. Sanderson \\
\hline SL3856 & like SLI 547 but cysE $E^{+}$ & - & see Methods \\
\hline SL3766 & like sL3 856 but $r f a L 446$ & TV225 & Kuo \& Stocker (1972) \\
\hline SL 3848 & like sL 3856 but $r f a L 447$ & TV226 & Kuo \& Stocker (I972) \\
\hline SL3849 & like sL 3856 but $r f a J 4 I 9$ & TVI66 & Kuo \& Stocker (1972) \\
\hline SL 3787 & like sL 3856 but $r f a($ R-res-2) $432 \dagger$ & TVI 48 & Kuo \& Stocker (1972) \\
\hline SL3854 & like $\mathrm{SL} 3856$ but $r f a G_{489}$ & SLIO62 & Kuo \& Stocker (1972) \\
\hline SL3790 & like $\mathrm{SL}_{3} 856$ but $r f a F_{5} I I$ & SLI I 8I & Kuo \& Stocker (1972) \\
\hline SL 3855 & like sL3856 but $r f a F 537$ & SLI I 82 & Kuo \& Stocker (1972) \\
\hline
\end{tabular}

* Genes $r f a J$ formerly designated $r f a($ R-res-I) are now known to indicate failure to add glucose II (Hellerqvist \& Lindberg, 1971).

$\dagger$ The lipopolysaccharide of strain TVI48 carrying gene $r f a(R-r e s-2) 432$ has been shown by methylation analysis to lack galactose I (Hellerqvist \& Lindberg, I97I).

\$ The gal-85I mutation does not affect the composition of the LPS.

Table 2. Second set of Salmonella typhimurium strains including galE, galU and rfaE mutants and their parent and derivative strains

\begin{tabular}{|c|c|c|c|}
\hline Strain & Genotype & Origin and description & Reference \\
\hline TV253 & $\begin{array}{l}\text { M747I (ColEI-30) leu-I05I } \\
\text { malB479 hisCrI50 cysGII75 }\end{array}$ & $\begin{array}{l}\text { From } \mathrm{M}_{7471^{*} ; \text { smooth parent of }} \\
\text { sL4510 and SL4507 }\end{array}$ & Krishnapillai et al. (1971) \\
\hline SL45IO & like TV253 but galE456† & $\begin{array}{l}\text { Mutant of TV253 (selection: FO } \\
+ \text { P22.c2 phages) }\end{array}$ & Krishnapillai et al. (197I) \\
\hline SL452I & like sL451o but $\mathrm{F}^{\prime} \mathrm{gal}^{+}$ & $\begin{array}{l}\text { SL45IO given } \mathrm{F}^{\prime}-\mathrm{Igal}^{+} \text {from } \\
\text { SL4516 } 6\end{array}$ & MacPhee \& Stocker (1969) \\
\hline SL4507 & like TV253 but galU455 & $\begin{array}{l}\text { Spontaneous mutant of TV253 } \\
\text { (selection: FO+P22.c2 phages) }\end{array}$ & see Methods \\
\hline SL459I & like SL4507 but $\mathrm{galU}^{+}$ & $\begin{array}{l}\text { Transductant of SL } 4507 \text { by } \\
\text { phage ESI } 8 \text { grown on SLI I } 83\end{array}$ & see Methods \\
\hline SL3622 & $\begin{array}{l}\text { SLIO27 (see below) lysogenized } \\
\text { by } \mathrm{P}_{22}\end{array}$ & P22-lysogenic SLI027 & see Methods \\
\hline SL4593 & like sL3622 but $\operatorname{trp} B^{+}$galU455 & $\begin{array}{l}\text { Transductant of SL3622 by } \\
\text { ESI } 8 . h 1 \text { grown on SL45O7 }\end{array}$ & see Methods \\
\hline SL4596 & like $\operatorname{sL3622}$ but $\operatorname{trp} B^{+}$ & $\begin{array}{l}\text { Transductant of SL3622 by } \\
\text { ESI } 8 . h 1 \text { grown on SL4507 }\end{array}$ & see Methods \\
\hline SLIO27 & $\begin{array}{l}\text { LT2 metA22 } \operatorname{trpB2} \mathrm{HI}-b \mathrm{~Hz}-e, n, x \\
\text { 'cured of Fels } 2 \text { ' flaA66 } \\
\text { strAI20 metE55I }\end{array}$ & Parent of SL 3622 & Wilkinson et al. (1972) \\
\hline SLI 102 & like sLIO27 but $r f a E_{543}$ & Heptose-less mutant of SLIO27 & Wilkinson et al. (1972) \\
\hline
\end{tabular}


Table 3. Minimum inhibitory concentrations of antibiotics for rfa transductants relative to those for smooth strains

Minimum inhibitory concentrations (see Methods) for the $r f a$ transductants are expressed relative to the m.i.c. (taken as I.0) for smooth strains (generally SLI515, but SLI547 for Meth). Absolute m.i.c. values for the comparison strains (expressed in $\mathrm{u}$. $\mathrm{ml}^{-1}$ for bacitracin and penicillin and $\mu \mathrm{g} \mathrm{ml}^{-1}$ for all other antibiotics) are given at the head of each column.

\begin{tabular}{|c|c|c|c|c|c|c|c|c|c|c|c|c|c|}
\hline $\begin{array}{l}\text { Strain* m. } \\
\text { Smooth }\end{array}$ & $\begin{array}{c}\text { Bac } \\
\text { m.i.c. (1 25) }\end{array}$ & $\begin{array}{l}\text { Vanco } \\
(\text { I75) }\end{array}$ & $\begin{array}{l}\text { Novo } \\
(500)\end{array}$ & $\begin{array}{l}\text { Ery } \\
(75)\end{array}$ & $\begin{array}{l}\text { P-m } \\
(0 \cdot 7)\end{array}$ & $\begin{array}{l}\text { N-m } \\
(4 \cdot 4)\end{array}$ & $\begin{array}{l}\text { Tet } \\
(I \cdot 0)\end{array}$ & $\begin{array}{l}\text { Ceph } \\
(I \cdot 25)\end{array}$ & $\begin{array}{l}\text { Pen } \\
(6)\end{array}$ & $\begin{array}{l}\text { Amp } \\
(0.6)\end{array}$ & $\begin{array}{l}\text { Oxa } \\
(200)\end{array}$ & $\begin{array}{l}\text { Naf } \\
(350)\end{array}$ & $\begin{array}{l}\text { Meth } \\
(400)\end{array}$ \\
\hline SLI 5 I 5 pyr & $I \cdot O$ & $1 \cdot 0$ & $I \cdot O$ & $I \cdot O$ & $1 \cdot 0$ & $I \cdot O$ & $1 \cdot 0$ & $I \cdot O$ & $1 \cdot 0$ & $I \cdot O$ & $I \cdot O$ & $I \cdot O$ & 0.8 \\
\hline SL3770 pyr ${ }^{+}$ & $I \cdot O$ & $1 \cdot 0$ & $I \cdot O$ & $I \cdot O$ & $I \cdot 0$ & $I \cdot O$ & $I \cdot O$ & $I \cdot O$ & $1 \cdot 0$ & $1 \cdot 0$ & $I \cdot O$ & $I \cdot O$ & $1 \cdot 2$ \\
\hline SLI 547 cys $^{-}$ & $I \cdot O$ & $I \cdot O$ & 0.9 & $I \cdot O$ & 0.9 & $I \cdot O$ & 0.9 & $I \cdot O$ & $1 \cdot 0$ & $I \cdot O$ & $I \cdot O$ & $I \cdot O$ & $I \cdot O$ \\
\hline $\begin{array}{l}\text { SL3856 cys }+ \\
\text { rfaL }\end{array}$ & $I \cdot O$ & $I \cdot 0$ & 0.9 & $I \cdot O$ & 0.9 & 0.9 & 0.9 & $I \cdot O$ & 0.8 & $I \cdot O$ & $I \cdot 0$ & 0.8 & 0 \\
\hline SL3749 pyr ${ }^{+}$ & $I \cdot 2$ & $I \cdot 0$ & $I \cdot 4$ & $I \cdot O$ & 0.9 & $I \cdot 3$ & $I \cdot 0$ & $1 \cdot 2$ & $I \cdot 3$ & $I \cdot 3$ & $I \cdot O$ & $I \cdot I$ & $1 \cdot 4$ \\
\hline SL3766 cys ${ }^{+}$ & $I \cdot 4$ & $I \cdot O$ & $I \cdot 4$ & $I \cdot O$ & 0.9 & $I \cdot I$ & $I \cdot 2$ & $I \cdot 4$ & $I \cdot 3$ & $I \cdot 3$ & $I \cdot O$ & $1 \cdot 0$ & $I \cdot 2$ \\
\hline $\begin{array}{l}\text { SL3848 } \text { cys }^{+} \\
\quad r f a J\end{array}$ & $I \cdot 4$ & $I \cdot O$ & $I \cdot 4$ & $I \cdot O$ & $I \cdot 0$ & $\mathrm{I} \cdot \mathrm{O}$ & $I \cdot 2$ & $I \cdot 6$ & $I \cdot 3$ & $I \cdot 3$ & $\mathbf{I} \cdot \mathbf{2}$ & $\mathbf{I} \cdot \mathbf{I}$ & $I \cdot 5$ \\
\hline $\begin{array}{l}\text { SL3750 pyr } \\
\text { SL3849 } \text { cys }^{+}\end{array}$ & $\begin{array}{l}I \cdot O \\
I \cdot 2\end{array}$ & $\begin{array}{l}I \cdot 0 \\
I \cdot 0\end{array}$ & $\begin{array}{r}I \cdot 4 \\
>I \cdot 4\end{array}$ & $\begin{array}{l}I \cdot O \\
I \cdot O\end{array}$ & $\begin{array}{l}0.6 \\
0.6\end{array}$ & $\begin{array}{l}I \cdot I \\
I \cdot I\end{array}$ & $\begin{array}{l}I \cdot 2 \\
I \cdot 4\end{array}$ & $\begin{array}{l}I \cdot 2 \\
I \cdot 6\end{array}$ & $\begin{array}{l}I \cdot 3 \\
I \cdot 6\end{array}$ & $\begin{array}{l}I \cdot 3 \\
-\end{array}$ & $\begin{array}{l}I \cdot 0 \\
I \cdot 2\end{array}$ & $\begin{array}{l}I \cdot I \\
I \cdot 3\end{array}$ & $\begin{array}{l}0.9 \\
I .5\end{array}$ \\
\hline $\begin{array}{l}r f a(\text { R-res-2 } \\
\text { sL.3748 pyr }\end{array}$ & $-2)$ & $1 \cdot 0$ & $<0.05$ & $\mathrm{I} \cdot \mathrm{O}$ & $0 \cdot \mathbf{I}$ & $1 \cdot 5$ & $I \cdot 4$ & $I \cdot 6$ & $I \cdot 6$ & $I \cdot 3$ & 0.7 & $I^{\prime} O$ & $\mathbf{I} \cdot \mathbf{I}$ \\
\hline $\begin{array}{c}\text { SL3787 cys }{ }^{+} \\
r f a G\end{array}$ & 0.6 & $I \cdot I$ & 0.05 & I $\cdot O$ & 0.1 & $1 \cdot 5$ & $1 \cdot 4$ & $2 \cdot 4$ & $2 \cdot 0$ & $2 \cdot 0$ & $I \cdot O$ & $I \cdot O$ & $\mathrm{I} \cdot 5$ \\
\hline SL3769 pyr ${ }^{+}$ & $0 \cdot 2$ & 0.4 & 0.05 & 0.5 & $0 \cdot I$ & $I \cdot I$ & $I \cdot 4$ & $1 \cdot 2$ & $1 \cdot 0$ & $1 \cdot 0$ & 0.2 & $0 \cdot 14$ & 0.5 \\
\hline $\begin{array}{l}\text { SL3854 } \text { cys }^{+} \\
\text {rfaF }\end{array}$ & 0.4 & 0.4 & 0.05 & 0.4 & $0 \cdot I$ & $\mathbf{I} \cdot \mathbf{I}$ & $I \cdot 4$ & $1 \cdot 6$ & $\mathrm{r} \cdot 6$ & $I \cdot 3$ & 0.2 & 0.3 & $I \cdot I$ \\
\hline L3789 pyr ${ }^{+}$ & 0.2 & 0.3 & $<0.05$ & 0.12 & $0 \cdot \mathbf{I}$ & $I \cdot I$ & $I \cdot 8$ & $1 \cdot 4$ & $I \cdot O$ & 0.7 & 0.2 & 0.14 & $0^{\circ}$ \\
\hline SL3790 cys $^{+}$ & 0.2 & 0.3 & $<0.05$ & 0.08 & $0 . I$ & $I \cdot O$ & $2 \cdot 0$ & $2 \cdot 4$ & $I \cdot O$ & $I \cdot O$ & $0 \cdot 2$ & 0.08 & $0^{\circ}$ \\
\hline SL3855 cys ${ }^{+}$ & 0.2 & 0.3 & $<0.05$ & $0 \cdot 16$ & $0 \cdot I$ & $I \cdot O$ & $2 \cdot 0$ & $2 \cdot 4$ & $I \cdot 3$ & $I \cdot 3$ & 0.2 & 0.5 & 0.8 \\
\hline
\end{tabular}

* The pyr ${ }^{+}$transductants are LT2 strains and the cys ${ }^{+}$transductants are LT7 strains.

resistance to phages FO and P22.c2. The galU455 gene was then transferred by phage ESı 8.hI into the smooth SL 3622 LT2 by cotransduction with $\operatorname{trp} B^{+}$, resulting in strain SL4593; sL4596 is a sister transductant receiving only the $\operatorname{trp} B^{+}$gene. The derivation of the heptose-less $r f a E$ mutant strain SLI 102 from its smooth parent strain SL1027 has been described (Wilkinson, Gemski \& Stocker, 1972).

Phages and phage methods. The phages used to select resistant mutants and to determine LPS by phage pattern tests were described by Wilkinson et al. (1972). Phage sensitivities were determined by the 'drop on lawn' method on nutrient agar or nutrient agar with galactose and glucose (each at $5 \mathrm{~g} \mathrm{l}^{-1}$ ). For transduction we used two phages: phage ESI 8, active on both smooth and non-smooth $S$. typhimurium, and its variant ESI 8.hI which, unlike ESI 8 itself, is fully active on strains lysogenic for Fels 2, carried by strain LT2 (Kuo \& Stocker, 1970). Lysogeny for P22 makes strains better recipients for ESI 8 transduction (Kuo \& Stocker, 1970) and strains not already lysogenic for P22 or a similar phage were made lysogenic before use as recipients.

\section{RESULTS}

The relative antibiotic resistances of the two sets of $r f a$ transductants together with those of their smooth parent and sister transductants are listed in Table 3. The $p y r^{+}$transductants are derived from the SLI5I5 pyrE LT2 smooth parent and the cys ${ }^{+}$transductants from the SLI547 cysE LT7 smooth parent. A value of $\mathrm{I} \cdot 0$ is assigned to the resistance (m.i.c.) of SLI5I5, except for methicillin where the $c y s$ parent and its $c y s^{+}$smooth transductant gave a more consistent reading; the corresponding absolute m.i.c. values are indicated. Values obtained for the smooth parents and their smooth transductants were either identical or nearly so for all antibiotics tested (Table 3).

Bacitracin (Bac). The $r f a L$ transductants showed slight (but consistent) increases in resistance; $r f a J$ transductants were as resistant as the smooth strains and $r f a(\mathrm{R}-\mathrm{res}-2)$ were 
about half as resistant. The $r f a G$ and $r f a F$ strains were more sensitive (relative m.i.c., 0.2 to 0.4 of control).

Vancomycin (Vanco). The $r f a$ transductants were as resistant as the smooth strains, except for the $r f a G$ and $r f a F$ strains which were considerably more sensitive (relative m.i.c., 0.3 to 0.4 ).

Novobiocin (Novo). The two more superficial $r f a$ classes ( $L$ and $J$ ) showed small but consistent increases in resistance, but there was a drastic decrease in resistance in the three deeper classes (R-res-2, $G$ and $F$ ) (relative m.i.c., 0.05 or less).

Erythromycin (Ery). The three more superficial classes were as resistant as the smooth strains; the $r f a G$ transductants were about one-half and the $r f a F$ about one-tenth as resistant.

Polymyxin B sulphate (P-m). The $r f a J$ transductants showed an increase in sensitivity (relative m.i.c., 0.6 ) and the three deeper classes a further more marked increase (relative m.i.c., $O \cdot I)$.

Neomycin (N-m). Except for slight increases (relative m.i.c., I.5) in resistance exhibited by the $r f a(\mathrm{R}-\mathrm{res}-2)$ transductants, the whole set had similar resistance to the smooth strains.

Tetracycline (Tet). All the $r f a$ transductants showed slight but very consistent increases in resistance (relative m.i.c., $\mathrm{I} \cdot 4$ to $2 \cdot 0$ ) compared with the smooth strains; $r f a F$ strains were the most resistant $(2 \cdot 0)$.

Cephalothin (Ceph). All classes of $r f a$ transductants were more resistant than the smooth strains with the $r f a\left(\right.$ R-res-2) $c y s^{+}$and $r f a F c y s^{+}$strains being the most resistant (relative m.i.c., 2·4).

Penicillin (Pen) and Ampicillin (Amp). Most classes showed slight increases in resistance, although the $r f a F$ strains were about as resistant as the smooth ones.

Oxacillin (Oxa), Nafcillin (Naf) and Methicillin (Meth). The three more superficial classes of $r f a$ strains showed similar or slightly increased resistances to these three antibiotics when compared with the smooth strains. The $r f a G$ and $r f a F$ transductants were considerably more sensitive to Oxa (relative m.i.c., 0.2$)$ and Naf $(0.08$ to 0.5$)$. This sensitivity of the two deeper $r f a$ classes was less evident with Meth (relative m.i.c., 0.5 to $\mathrm{I} \cdot \mathrm{I}$ ).

The above results indicated that LPS defects including absence of $O$ side-chains caused moderate increases in resistance to some antibiotics ( $\mathrm{I} \cdot \mathrm{I}$-fold to $2 \cdot 4$-fold) compared with the resistances of the smooth strains. They also showed that defects in the deeper part of the core [rfa(R-res-2) and, more often and to a greater extent, $r f a G$ and $r f a F]$ caused considerably greater sensitivity to those antibiotics which are less effective against Gramnegative than against Gram-positive bacteria (Bac, Vanco, Novo, Ery, Oxa, Naf) and also to polymyxin.

Strains with LPS core-defects similar to those of the $r f a($ R-res-2) and $r f a G$ transductants could be investigated by testing galE or galU mutants. The effect of a deeper defect than those of the $r f a F$ strains could be investigated by comparing the antibiotic resistances of an $r f a E$ heptose-less mutant (see Fig. I) with those of its parent smooth strain. The descriptions of these strains are shown in Table 2.

The polysaccharide core of a galE mutant differs from that of a $r f a(\mathrm{R}-\mathrm{res}-2)$ mutant in that it contains neither galactose unit whereas the latter has galactose II (see Fig. I). The parent strain of our galE mutant was TV253, a smooth virulent auxotrophically marked strain in an S. typhimurium FIRN line (lacks fimbriae, fails to ferment inositol and rhamnose; see Morgenroth \& Duguid, 1968). Results from testing this mutant along with its parent and its derivative strain given an F' $g a l$ which 'cures' the galE defect are listed in Table 4, which shows absolute m.i.c. values. The $r f a(\mathrm{R}$-res-2) transductants (Table 3 ) in LT2 and LT7 lines showed increased sensitivity to Bac, Novo and P-m. The galE mutant showed similar increases in sensitivity to Bac and P-m but was more resistant than its comparable smooth strains to Novo. The $r f a(\mathrm{R}$-res-2) strains were more resistant than the smooth strains to Tet, Ceph, Pen and Amp as was the galE mutant, although its increase in resistance to Tet was 


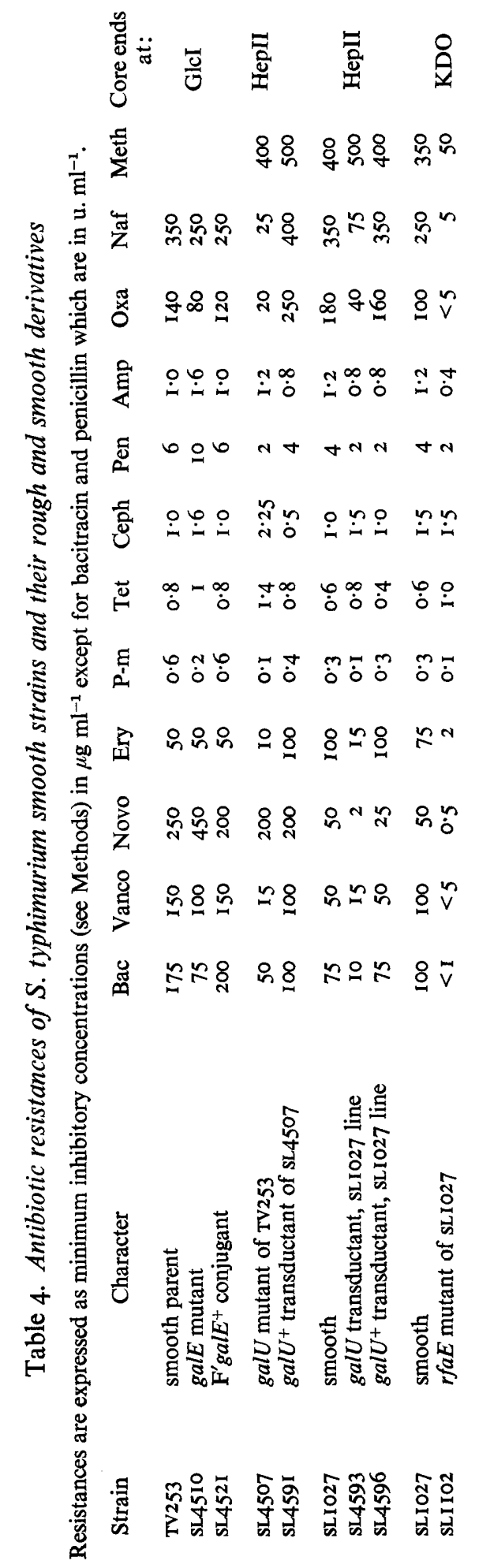


Table 5. Comparison of the relative minimum inhibitory concentrations of the LT2 and LT7 rfaG transductants, the LT2 galU transductant and the galU FIRN mutant

The minimum inhibitory concentrations of rough strains are expressed relative to the m.i.c. (taken as 1.0 ) of their smooth comparison strains. Smooth comparison strains for $r f a G$ transductants are as in Table 3; those for the galU strains are their galU ${ }^{+}$transductants (Table 4).

Strain

LT2 $r f a G$ (SL3769)

LT7 $r f a G$ (SL3854)

LT2 $\mathrm{galU}$ (SL4593)

FIRN galU (SL4507)

$\begin{array}{llllllllllll}\text { Bac } & \text { Vanco Novo Ery } & \text { P-m } & \text { Tet } & \text { Ceph } & \text { Pen } & \text { Amp } & \text { Oxa } & \text { Naf } & \text { Meth } \\ 0.2 & 0.4 & 0.05 & 0.5 & 0.1 & I .4 & I \cdot 2 & I .0 & I \cdot 0 & 0.2 & 0.14 & 0.5 \\ 0.4 & 0.4 & 0.05 & 0.4 & 0.1 & I .4 & I .6 & I .6 & I \cdot 3 & 0.2 & 0.3 & I \cdot 1 \\ 0.13 & 0.3 & 0.08 & 0.15 & 0.3 & 2.0 & 1.5 & I .0 & 1 \cdot 0 & 0.2 & 0.2 & I \cdot 2 \\ 0.5 & 0.15 & 1.0 & 0.1 & 0.25 & 1.7 & 4.5 & 0.5 & 1.5 & 0.06 & 0.08 & 0.8\end{array}$

Table 6. Comparison of the relative minimum inhibitory concentrations of the rfaF transductants and the rfaE mutant

\begin{tabular}{|c|c|c|c|c|c|c|c|c|c|c|c|}
\hline Strain & Bac & Vanco Novo & Ery & P-m & Tet & Ceph & Pen & Amp & Oxa & Naf & Meth \\
\hline$a F($ SL3789) & 0.2 & $0.3<0.05$ & 0.12 & 0.1 & $\mathrm{I} \cdot 8$ & $I \cdot 4$ & $I \cdot O$ & 0.7 & 0.2 & 0.14 & 0.5 \\
\hline$a F($ SL3790) & 0.2 & $0.3<0.05$ & 0.08 & $0 . I$ & $2 \cdot 0$ & $2 \cdot 4$ & $1 \cdot 0$ & $I \cdot O$ & 0.2 & 0.08 & 0.7 \\
\hline$F($ SL 3855) & 0.2 & $0.3<0.05$ & $0 \cdot 16$ & $0 \cdot I$ & $2 \cdot 0$ & $2 \cdot 4$ & $1 \cdot 3$ & $I \cdot 3$ & 0.5 & 0.2 & 0.8 \\
\hline$a E$ (SLI IO2) & $<0.0$ & $I<0.05 \quad 0.01$ & 0.03 & 0.3 & $I \cdot 7$ & $I \cdot O$ & 0.5 & 0.3 & $<0.05$ & 0.02 & 0.15 \\
\hline
\end{tabular}

slight. Against the other antibiotics tested (Vanco, Ery, Naf and Oxa), rfa(R-res-2) strains showed about the same sensitivities as the smooth controls; the galE mutant behaved similarly except that it was slightly more sensitive to Vanco and Oxa than the smooth strains. These results can probably be attributed to the effect of the mutation because the presence of $\mathrm{F}^{\prime} \mathrm{gal}^{+}$results in a strain with antibiotic resistances very similar or identical to those of the smooth parent.

The galU mutants are unable to synthesize UDPglucose and hence do not incorporate glucose into the rough core (Nakae \& Nikaido, I97I). Their core, then, should be the same as that of $r f a G$ mutants that cannot attach glucose I (Fig. I). Our galU455 mutant (SL4507) was derived in the same line (FIRN) as the galE mutant. Its antibiotic resistances are compared in Table 4 with those of its derivative (SL459I) made $g a l U^{+}$by transduction and with those of a smooth $\operatorname{trpB}$ LT2 strain (SLI027), and its galU455 cotransductant (galU455 trpB $B^{+}$) and its $\operatorname{trp} B^{+}$only transductant derivatives (SL4593 and SL4596, respectively).

The m.i.c. values of the $r f a G$ LT2 and LT7 transductants, the galU LT2 transductant (SL4593) and the galU FIRN mutant relative to those of their smooth transductant counterparts (taken as $\mathrm{I} \cdot 0$ ) are shown in Table 5. The galU defect appears to cause qualitative changes in antibiotic resistances similar to those shown by the $r f a G$ strains. Except for Novo resistance the galU defect exerts quite similar effects on the other resistances whether expressed in the LT2 or FIRN background. As in the galE mutants, it is evident that the mutation is responsible for the observed change since otherwise isogenic smooth strains possess the smooth phenotype in regard to antibiotic resistances.

The deepest rough mutation we could test was $r f a E$. The resistances of the $r f a E$ mutant and of the $r f a F$ transductants relative to those of their smooth counterparts (I $\cdot 0)$ are shown in Table 6. The $r f a E$ mutant was more sensitive to all antibiotics tested (except P-m) than the $r f a F$ strains that contain heptose in their core (Fig. I). But even with this deep defect, the $r f a E$ mutant is as resistant to Ceph as its smooth parent and is more resistant to Tet. 


\section{DISCUSSION}

The results from tests with the two sets of $r f a$ transductants, the galU strains and the $r f a E$ mutant agree in that strains belonging to the three deepest levels tested ( $r f a G-g a l U, r f a F$, $r f a E$ ) were substantially more sensitive than their smooth comparison strains to certain antibiotics relatively inactive against Gram-negative enteric bacilli (Bac, Vanco, Ery, $\mathrm{Naf}, \mathrm{Oxa})$. They were also more sensitive to polymyxin. Strains belonging to the $r f a(\mathrm{R}-\mathrm{res}-2)$ class were more sensitive than the smooth strains to Bac, Novo and P-m; the galE mutant (FIRN line), which might be expected to be similar to the $r f a(\mathrm{R}-\mathrm{res}-2)$ class, was also sensitive to Bac and P-m, but showed increased resistance to Novo rather than the expected greater sensitivity. Except for resistance to Novo, the galU strains resembled the $r f a G$ strains in their resistances. The galU FIRN mutant was no more sensitive to Novo than its smooth $\mathrm{galU}^{+}$counterpart (relative m.i.c., I·O), but the galU transductant in the LT2 line was considerably more sensitive (relative m.i.c., 0.08) than its galU ${ }^{+}$sister transductant and, in this, resembled the $r f a G$ LT2 and LT7 strains (relative m.i.c., 0.05). At least in sensitivity to Novo, the galE and galU strains in the FIRN line appear to differ from the transductants in the LT2 line. This may indicate some unknown difference in the rough core at this level of these two distinct $S$. typhimurium lines.

The $r f a$ transductants of several classes showed rather small but consistent increases in resistance to certain antibiotics (notably Tet, Ceph, Amp, Pen) in comparison with the smooth strains. Such results are in accordance with the observation that mutants selected for resistance to cephalothin or penicillin are often rough strains of various classes (Nelson \& Roantree, 1967).

These results are in essential agreement with those of Schlecht and his colleagues who tested mutants of different rough chemotypes in Salmonella ruiru, S. typhimurium and Salmonella minnesota (Schlecht \& Schmidt, 1970, 1972; Schlecht \& Westphal, 1970). They found that the rough strains, and particularly the deeper rough strains, were more sensitive than smooth control strains to rifamycin and actinomycin as well as to Bac, Vanco and Ery. The increases in resistance of some classes to Tet and Pen were also noted. In general, their results show somewhat more variation within rough classes than we found. The effect of the presence or absence of a particular sugar (e.g. glucose I for Vanco or Ery resistance) although evident, is not as clearcut as in our series. This may be partly because their methods of measuring antibiotic sensitivities by streaking a loopful of each test strain on to a gradient plate and measuring the length of the streak of growth allows less precise quantification than ours. In addition the test strains at their disposal were less genetically homogeneous than ours. For example, some $S$. minnesota deep rough strains in their set have been shown to contain mutations in addition to the suspected $r f a$ mutation. Some contain an additional $r f a P$ mutation in a gene which governs the phosphorylation of heptose in the rough core (Mühlradt et al., 1968; Jousimies \& Mäkelä, 1974) and some contain an additional rfe mutation in a gene necessary for the synthesis of $O$ side-chains and the common antigen in this species (Mäkelä et al., 1974). The effect of the $r f a P$ mutation on the deep core could conceivably influence antibiotic sensitivities. Our use of sets of transductants should largely avoid the problem of multiple mutations.

The $r f a E$ heptose-less mutant is much more sensitive to most of the antibiotics more effective against deep rough strains than the heptose-containing $r f a F$ transductants (Table 6). Even at the $r f a E$ level, though, penicillin-sensitivity is only moderately greater (relative m.i.c., 0.5) than that of the smooth strain. Since a Io times greater concentration of penicillin is necessary to inhibit growth of Escherichia coli than to inhibit transpeptidation in a cellfree system (Strominger et al., 1967), one might have expected a lower relative m.i.c. than 0.5 with this very defective LPS unless the outer membrane contains a further barrier to penicillin penetration.

We believe the most attractive hypothesis put forward to explain the greater sensitivity 
of the deep rough strains to certain antibiotics is that of Nikaido (1976). He postulates that hydrophilic molecules of less than 650 daltons gain entrance to the periplasmic space through water-filled, protein-lined pores in the outer membrane. Thus the outer membrane should not be the barrier to such molecules that it would be to hydrophobic molecules or hydrophilic ones of greater molecular weight. He measured the partition coefficient (I-octanol/water system) of a number of the antibiotics and dyes used by Schlecht and his colleagues (Schlecht \& Schmidt, 1970; Schlecht \& Westphal, 1970; Schmidt, Schlecht \& Westphal, 1969) and of antibiotics used in our study. Nearly all of the antibiotics tested which were more active against the deep rough strains fell into the hydrophobic class or had molecular weights greater than 650. Polymyxin is amphiphilic but has a molecular weight of about 1200. It reacts with LPS (Rifkind, 1967) as well as the phospholipids and may create its own holes. The [fact that treatment with polymyxin rendered Proteus mirabilis sensitive to killing by deoxycholate (Sud \& Feingold, 1972) lends credence to such a concept. Almost all of the antibiotics which were equally active against smooth and rough strains were hydrophilic and less than 650 daltons. Chloramphenicol and tetracycline were exceptions in that they were hydrophobic, but Nikaido notes that tetracycline probably penetrates as a magnesium complex and that chloramphenicol, perhaps, penetrates by means of a specific mechanism. Previous work (Ames, Spudich \& Nikaido, 1974) had shown that the outer membranes of mutants lacking the glucose I unit and those with deeper defects lacked considerable amounts of the proteins making up four major bands $(33 \mathrm{~K}, 34 \mathrm{~K}, 35 \mathrm{~K}, 36 \mathrm{~K})$ on sodium dodecyl sulphate-polyacrylamide electrophoretic analysis. Three of these proteins $(34 \mathrm{~K}, 35 \mathrm{~K}, 36 \mathrm{~K})$ are those necessary to form aqueous pores in reconstituted LPS-phospholipid bilayers (Nakae, 1976). Thus Nikaido believes that the loss of such proteins leads to a rearrangement in the structure of the outer membrane allowing areas of phospholipid to be present at the surface (Smit, Kamio \& Nikaido, 1975). Hence hydrophobic molecules could gain access to the periplasmic space by dissolving in the lipid bilayer.

Our findings are generally consistent with Nikaido's hypothesis in that for most antibiotics more effective against deep rough strains a definite change occurs at the $r f a G$ level. The finding that $r f a($ R-res-2) and the galE strains were more sensitive to some of the antibiotics than strains with more superficial lesions may not be at odds with the hypothesis since the outer membrane of galE mutants lacks measurable amounts of the $34 \mathrm{~K}$ and $35 \mathrm{~K}$ proteins (Ames et al., 1974).

A number of mutants with defects in the outer membrane and changes in permeability to a variety of agents have been reported. Salmonella typhimurium strains with reduced amounts of $34 \mathrm{~K}$ to $36 \mathrm{~K}$ proteins and presumed to be outer membrane protein mutants (Ames et al., 1974) allow rapid penetration of hydrophobic molecules. Several S. typhimurium mutants (FOR) selected for resistance to Felix-O phage appear smooth by other criteria but are sensitive to those antibiotics to which the deep rough strains are susceptible (MacPhee et al., I975). Felix-O resistance mapped in the $r f a$ region and it is thought that the FOR mutations affect the assembly of the inner part of the LPS core causing incomplete blocks in glycosyl transferase reactions. Escherichia coli mutants supersensitive to novobiocin and with increased sensitivity to such antibiotics as bacitracin and actinomycin have outer membranes very deficient in heptose, glucose and phosphate (Tamaki, Sato \& Matsuhashi, I97I ; Tamaki \& Matsuhashi, 1973). An E. coli mutant defective in an outer membrane protein was found to be sensitive to dyes and detergents (Wu, 1972). In E. coli $\mathrm{K} I 2$ the envA mutation results in incomplete cell division, a relative decrease in the content of phosphatidyl ethanolamine in the outer membrane, and greatly increased sensitivity to penicillin, ampicillin and chloramphenicol as well as to a number of the antibiotics that we found to be more effective against deep rough strains (Boman, Nordström \& Normark, 1974). This may indicate that the phospholipid composition of the outer membrane is important in the penetration of penicillin. Escherichia coli mutants sensitive to synergistin A are sensitive to many of the antibiotics that are more effective against the deep rough strains (Ennis, I97I). 
Increased sensitivities to those antibiotics more effective against the deep rough strains have been found when $E$. coli or Salmonella have been treated with EDTA. Thus treatment with EDTA and lysozyme to produce protoplasts allowed access of actinomycin D into E. coli (Mach \& Tatum, 1963) and, indeed, EDTA treatment alone can increase the permeability to this antibiotic (Leive, 1968). Muschel \& Gustafson (1968) showed that EDTA treatment rendered Salmonella typhi more sensitive to polymyxin, novobiocin and certain detergents and, to a lesser extent, more sensitive to bacitracin and penicillin. However, such treatment had little or no effect on the sensitivity to streptomycin, neomycin, kanamycin, chloramphenicol or chlortetracycline. In their resistances to these agents, EDTA-treated coliforms are much like deep rough strains. Treatment with EDTA results in the release of 30 to $50 \%$ of the LPS from the outer membrane (Leive, 1965) presumably through the interaction of EDTA with $\mathrm{Ca}^{2+}$ and/or $\mathrm{Mg}^{2+}$ ions (Leive, 1974). The released material contains 5 to $10 \%$ protein (Leive, Shovlin \& Mergenhagen, 1968). Perhaps phospholipid patches are created or uncovered by such treatment to allow penetration of hydrophobic molecules.

The increase in resistance to certain antibiotics, particularly Tet, Ceph, Amp and Pen, of many of the $r f a$ classes is perhaps more difficult to explain than the increased sensitivitities. As noted above, both our results and those of Schlecht and his colleagues agree that this phenomenon is real. In addition, it has been shown that among ampicillin-resistant mutants of $E$. coli KI2 are a number with outer membrane defects (Eriksson-Grennberg, Nordström \& Englund, 197I; Monner, Jonsson \& Boman, 197I) including various deficiencies of the polysaccharide portion of the LPS core (Boman \& Monner, 1975; Mayer et al., 1976). Since the antibiotics listed above are, according to the Nikaido hypothesis, those likely to penetrate through the water-filled pores, perhaps loss of polysaccharide distorts these channels so as to hinder the access of the antibiotics. If the increases in resistance were limited to those classes with defects deeper than the glucose I $(r f a G)$ level one might postulate a quantitative loss of the protein-lined pores, but our data do not allow this interpretation since some more superficial $r f a$ strains show the increases in resistances.

The results of our experiments emphasize the importance of the outer membrane of Salmonella in preventing access of certain antibiotics, notably those less active against Gram-negative than against Gram-positive organisms. The presence or absence of single sugars from the polysaccharide of the LPS can make a considerable difference. Paradoxically some rough classes are more resistant to antibiotics which are effective against Gramnegative bacteria.

This work was supported by U.S. Public Health Service research grants AI 02755 and AI Q7168 and training grant AI 00082 from the National Institute of Allergy and Infectious Diseases.

\section{REFERENCES}

Ames, G. F. L., Spudich, E. N. \& Nikamo, H. (1974). Protein composition of the outer membrane of Salmonella typhimurium: effect of lipopolysaccharide mutations. Journal of Bacteriology II7, 406-416.

Boman, H. G. \& MonNeR, D. A. (1975). Characterization of lipopolysaccharides from Escherichia coli $\mathbf{k} 12$ mutants. Journal of Bacteriology 121, 455-464.

Boman, H. G., Nordström, K. \& Normark, S. (1974). Penicillin-resistance in Escherichia coli KI2: synergism between penicillinases and a barrier in the outer part of the envelope. Annals of the New York Academy of Sciences 253, 569585 .
ENNIs, H. L. (197I). Mutants of Escherichia coli sensitive to antibiotics. Journal of Bacteriology ro7, 486-490.

ERIKSSON-GrenNBERG, K. G., NordSTröM, K. \& ENGLUND, P. (197I). Resistance of Escherichia coli to penicillins. IX. Genetics and physiology of class II ampicillin-resistant mutants that are galactose negative or sensitive to bacteriophage C21 or both. Journal of Bacteriology 108, 1210 1223.

Hellerqvist, C. G. \& LindberG, A. A. (1971). Structural studies of the common core polysaccharide of the cell-wall lipopolysaccharide from Salmonella typhimurium. Carbohydrate Research I6, 39-48. 
Jousimies, H. \& MÄKelÄ, P. H. (I974). Genetic analysis of Salmonella minnesota $\mathbf{R}$ mutants with defects in the biosynthesis of the lipopolysaccharide core. Journal of Bacteriology 119, 753-759.

Krishnapillai, V., MacPhee, D. G. \& Stocker, B. A. D. (197I). Properties of a Salmonella typhimurium mutant with an incomplete deficiency of uridinediphosphogalactose-4-epimerase. Journal of Bacteriology 107, I 55-16I.

Kuo, T.-T. \& STOCKer, B. A. D. (I970). ESI 8, a general transducing phage for smooth and nonsmooth Salmonella typhimurium. Virology 42, $62 \mathrm{I}-632$.

Kuo, T.-T. \& Stocker, B. A. D. (1972). Mapping of $r f a$ genes in Salmonella typhimurium by $\mathrm{ES}_{1} 8$ and $\mathrm{P}_{22}$ transduction and by conjugation. Journal of Bacteriology 112, 48-57.

LEIVE, L. (I965). Release of lipopolysaccharide by EDTA treatment of E. coli. Biochemical and Biophysical Research Communications 2r, 290-296.

LEIVE, L. (I968). Studies on the permeability change produced in coliform bacteria by ethylenediaminetetraacetate. Journal of Biological Chemistry 243, 2373-2380.

LeIVE, L. (1974). The barrier function of the gramnegative envelope. Annals of the New York Academy of Sciences 235, 109-1 27.

Leive, L., Shovlin, V. K. \& Mergenhagen, S. E. (I968). Physical, chemical, and immunological properties of lipopolysaccharide released from Escherichia coli by ethylenediaminetetraacetate. Journal of Biological Chemistry 243, 6384-6391.

MACH, B. \& TATUM, E. L. (1963). Ribonucleic acid synthesis in protoplasts of Escherichia coli: inhibition by actinomycin D. Science 139, I05II052.

MacPhee, D. G., Krishnapillai, V., Roantree, R. J. \& STOCKeR, B. A. D. (1975). Mutations in Salmonella typhimurium conferring resistance to Felix $O$ phage without loss of smooth character. Journal of General Microbiology 87, I-IO.

MacPhee, D. G. \& Stocker, B. A. D. (1969). Suppression of amber and ochre mutants in Salmonella typhimurium by a mutant $F^{\prime}$-I-gal factor carrying an ochre suppressor gene. Journal of Bacteriology roo, 240-246.

Mäkelä, P. H., MAYer, H., Whang, H. Y. \& NeTER, E. (1974). Participation of lipopolysaccharide genes in the determination of the enterobacterial common antigen: analysis of $\mathbf{R}$ mutants of Salmonella minnesota. Journal of Bacteriology Ir9, 760-764.

MAYer, H., RapiN, A. M. C., Schmidt, G. \& Boman, H. G. (I976). Immunochemical studies on lipopolysaccharides from wild-type and mutants of Escherichia coli K12. European Journal of Biochemistry 66, 357-368.

MonNer, D. A., Jonsson, S. \& Boman, H. G. (I97I). Ampicillin-resistant mutants of Escherichia coli KI 2 with lipopolysaccharide alterations affecting mating ability and susceptibility to sex-specific bacteriophages. Journal of Bacteriology 107, 420432.

Morgenroth, A. \& Duguid, J. P. (1968). Demonstration of different mutational sites controlling rhamnose fermentation in FIRN and non-FIRN rhamnose-negative strains of Salmonella typhimurium: an essay in bacterial archaeology. Genetical Research 11, 151-169.

MüHLRADT, P., RisSE, H. J., LüDERITZ, O. \& WeSTPHAL, O. (I968). Biochemical studies on lipopolysaccharides of Salmonella $\mathbf{R}$ mutants. 5 . Evidence for a phosphorylating enzyme in lipopolysaccharide synthesis. European Journal of Biochemistry 4, I 39-I 45.

Muschel, L. H. \& Gustafson, L. (1968). Antibiotic, detergent, and complement sensitivity of Salmonella typhi after ethylenediaminetetraacetic acid treatment. Journal of Bacteriology 95, 20102013.

NAKAE, T. (1976). Outer membrane of Salmonella. Isolation of protein complex that produces transmembrane channels. Journal of Biological Chemistry 251, 2176-2178.

NAKAE, T. \& NIKAIDO, H. (197I). Multiple molecular forms of uridine diphosphate glucose pyrophosphorylase from Salmonella typhimurium. II. Genetic determination of multiple forms. Journal of Biological Chemistry 246, 4397-4403.

Nelson, B. W. \& Roantree, R. J. (I967). Analyses of lipopolysaccharides extracted from penicillinresistant, serum-sensitive Salmonella mutants. Journal of General Microbiology 48, 179-188.

NikaIDO, H. (1976). Outer membrane of Salmonella. Transmembrane diffusion of some hydrophobic molecules. Biochimica et biophysica acta 433, I $18-132$.

OSBORN, M. J. (1968). Biochemical characterization of mutants of Salmonella typhimurium lacking glucosyl or galactosyl lipopolysaccharide transferases. Nature, London 217, 957-960.

RIFKIND, D. (1967). Studies on the interaction between endotoxin and polymyxins. Journal of Infectious Diseases 117, 433-438.

Roantree, R. J., Kuo, T.-T., MacPhee, D. G. \& STOCKER, B. A. D. $(1969 a)$. The effect of various rough lesions in Salmonella typhimurium upon sensitivity to penicillins. Clinical Research 77, I57.

Roantree, R. J., Kuo, T.-T., MacPhee, D. G. \& STOCKER, B. A. D. $(1969 b)$. Effect of various rough lesions in Salmonella typhimurium upon sensitivity to antibiotics. Bacteriological Proceedings, 79.

Sanderson, K. E. \& Saeed, H. (1972). Insertion of the $\mathrm{F}$ factor into the cluster of $r f a$ (rough $\mathrm{A}$ ) genes of Salmonella typhimurium. Journal of Bacteriology $112,58-63$.

Sanderson, K. E. \& Saeed, Y. A. (1972). P22mediated transduction of the rough A ( $r f a)$ genes of Salmonella typhimurium. Journal of Bacteriology I12, 64-73.

SCHLECHT, S. \& SCHMidT, G. (I969). Möglichkeiten zur Differenzierung von Salmonella-R-Formen mittels Antibiotica und antibakterieller Farbstoffe. Zentralblatt für Bakteriologie, Parasitenkunde, Infektionskrankheiten und Hygiene (Abteilung I) 212, 505-5II.

Schlecht, S. \& Schmidt, G. (1970). Untersuchungen zur Typisierung von Salmonella-R-Formen. 5 Mitteilung: Untersuchungen an Salmonella 
ruiru Mutanten. Zentralblatt für Bakteriologie, Parasitenkunde, Infektionskrankheiten und $\mathrm{Hy}$ giene (Abteilung I) 215, 196-202.

SCHLECHT, S. \& SCHMIDT, G. (1972). Untersuchungen zur Typisierung von Salmonella-R-Formen. 6 Mitteilung: Untersuchungen an Salmonella typhimurium Mutanten. Zentralblatt für Bakteriologie, Parasitenkunde, Infektionskrankheiten und Hygiene (Abteilung I) 219, 480-493.

SChleCHT, S. \& WestPhal, O. (1970). Untersuchungen zur Typisierung von Salmonella-RFormen. 4 Mitteilung: Typisierung von $S$. minnesota R-Mutanten mittels Antibiotica. Zentralblatt für Bakteriologie, Parasitenkunde, Infektionskrankheiten und Hygiene (Abteilung I) 213, 356-38I.

Schmidt, G., Schlecht, S. \& WeStPhal, O. (1969). Untersuchungen zur Typisierung von SalmonellaR-Formen. 3 Mitteilung: Typisierung von $S$. minnesota R-Mutanten mittels chemischer Agenzien. Zentralblatt für Bakteriologie, Parasitenkunde, Infektionskrankheiten und Hygiene (Abteilung I) 212, 88-96.

Smit, J., Kamio, Y. \& Nikamo, H. (1975). Outer membrane of Salmonella typhimurium: chemical analysis and freeze-fracture studies with lipopolysaccharide mutants. Journal of Bacteriology I24, 942-958.
Strominger, J. L., Izaki, K., Matsuhashi, M. \& TIPPER, D. J. (1967). Peptidoglycan transpeptidase and D-alanine carboxypeptidase: penicillinsensitive enzymatic reactions. Federation Proceedings $26,4-28$.

Sud, I. J. \& FeIngold, D. S. (1972). Effect of polymyxin $\mathrm{B}$ on antibiotic resistant Proteus mirabilis. Antimicrobial Agents and Chemotherapy I, 4I 7-42I.

TAMAKI, S. \& MATSUHASHI, M. (1973). Increase in sensitivity to antibiotics and lysozyme on deletion of lipopolysaccharides in Escherichia coli strains. Journal of Bacteriology II4, 453-454.

TAMAKI, S., SATo, T. \& MatsuHaShI, M. (197I). Role of lipopolysaccharides in antibiotic resistance and bacteriophage adsorption of Escherichia coli $\mathbf{K 1} 2$. Journal of Bacteriology 105, 968-975.

Wilkinson, R. G., Gemski, P. \& Stocker, B. A. D. (1972). Non-smooth mutants of Salmonella typhimurium: differentiation by phage sensitivity and genetic mapping. Journal of General Microbiology 70, 527-554.

Wu, H. C. (1972). Isolation and characterization of an $E$. coli mutant with alteration in the outer membrane proteins of the cell envelope. Biochimica et biophysica acta 290, 274-289. 